\title{
A QUINTESSENTIALLY ENGLISH GLOVE LEGACY
}

\author{
FRANCES TURNER
}

BATH SPA UNIVERSITY, ENGLAND

\section{KEYWORDS}

Glove design

Glove makers

Dents

Artisan

Embellished

Craftsmanship

Heritage

Fashion Museum

English culture

Worcester Museum

\section{ABSTRACT}

The English artisan skills required to produce exquisitely embellished, leather gloves is an important English legacy. The historic cities of Worcester and Bath have, since the 17th Century, been centres of craftsmanship for Glove makers and Design. There is something quintessentially English in the narrative of this heritage having strong connection to English culture and branding.

Three important archival glove collections are housed in the Fashion Museum, Bath, the Museums Worcestershire collection and Dents Gloves.

The paper will uncover the story of English glove design, manufacturing and social time whilst exploring the relevance of these collections for designers and makers today. 
$\mathrm{T}$ his is not just the story of the quintessentially English glove legacy but is the story of the lives of those who produced, owned and wore them. It is a multidisciplinary approach during which there has been the opportunity to assess the material objects alongside rich textual writings. Primary research has included the viewing and handling of gloves from across a time span of 400 years and artefacts from glove production across the last 200 years.

My paper starts in the city of Worcester which was a significant centre of the English leather glove-making industry, notably from the late 18th century onwards (and records show that gloves were being made there from as early as the 13 th century).

Important archives exist today from glove manufacturing that include not only the gloves themselves but artefacts connected with making gloves: collections held by the Fashion Museum in Bath, Museums Worcestershire and Dents Gloves (who hold what is thought to be one of the largest collections of privately-owned gloves) have proved informative and fascinating sources of the design and make of gloves. All three hold stunning collections associated with Worcester-made gloves and English gloves. These collections have examples of a variety of gloves that were once made and worn by people from a wide social spectrum, including adults and children. The survival of these gloves and artefacts, diverse and random though they are, allow an attempt at an analysis of the social times in which they were both made and worn, perhaps reflecting the factual and emotional story of their lives. It is a biography of the gloves themselves as well as being a micro-historical analysis of the glove makers and wearers, revealing layers of social and cultural complexity involved from the starting point of a tannery to the final social and sartorial impact upon wear, be it practical or as part of a special occasion wear to assert social standing. The paper looks not only at the item themselves but at the stories of the makers, wearers, interpreters of dress and why it is relevant today to dress historians, designers, and those who are interested in advancing a sustainable fashion industry.

It is an attempt to span the gap between the written history of the significance of glove design, glove manufacturing as well as connecting them to the individuals to whom they belonged and were worn by, encompassing many levels of experience. The story would not be complete without those men and women whose daily working lives produced the gloves that then moved into the ownership of the middle classes, aristocracy, and royalty or famous English characters. Nor would it be complete without the background to the centre of the industry and the rationale as to why much significant glove-making was focussed in a particular geographical location that grew in importance but then rapidly declined after the mid-20th century.

It is a multidisciplinary study to gain an understanding of the development of the leather gloving industry as well as the gloves themselves and the wider social impact as well as the practical aspect. As Kate Strasdin comments: "material culture methodologies can demand more of dress than simply its place in time." (2017: 4) Gloves can be linked to the livelihoods of tanners, glove makers, designers, and those who wore them at specific social times.

Having the opportunity to hold and assess gloves and artefacts from museums and private collections alongside valuable documented records has provided a much-needed multidisciplinary approach to this specific area of research. Valerie Steele noted in 1998: "Because Intellectuals live by the word, many scholars tend to ignore the important role that objects can play in the creation of knowledge. Even many fashion historians spend little or no time examining actual garments, preferring to rely exclusively on written sources and visual representations." (1998: 327)

\section{Why Gloves are important research material to understand social and fashion history}

An atmosphere of romance has long surrounded the glove in England and it has been associated with many emotions and sentiments. Perfumed gloves were a very popular luxury in several European countries including England, reaching the height of their popularity in 16th and 17thcentury fashion although evidence suggests scented gloves had existed in the 14th century. Elizabeth I, Queen of England and Ireland in the late 16th century owned many perfumed gloves in her personal glove collection. She displayed her power and status through her extravagant 
dress and appearance and wore exquisitely hand-embroidered gowns encrusted with precious jewels including diamonds, rubies, and sapphires.

Members of the royal court and in high echelons of society desired gloves that were perfumed with a range of special fragrances. John Redwood describes the most popular fragrances and how they could be used: "Perfumes for gloves included musk, ambergris, aloe, clove, jasmine and rose. A simple way of creating and maintaining a low level of perfuming was to store the gloves in drawers or boxes containing perfume sachets. Jasmine could be made up into a type of butter and put on the flesh or inside of the leather, or even on the gloves themselves." (2016:28) Other fragrances included water of orange flower, oil of sweet almonds, nutmeg and oil of lemon amongst others. Perfumed gloves were an extravagance amongst the elite, and the use of fragrance on gloves then led to its use on other kinds of clothing and then onto its use on human skin directly.

In addition to the use of perfume, gloves were also finely embroidered by hand and this sometimes included the embellishment of metal thread lace in silver and gold, precious jewels and tassels. In the 17th century, heavily embellished gloves provided an opportunity to display an individual's wealth and social position. The lace and embroidery were handcrafted by master craftsmen, often working in professional workshops. Embroidered gloves were treasured possessions, they were frequently gifted at significant occasions, such as to wedding guests or at the New Year, and they were exchanged between lovers.

There was a time when neither women, men nor children of high social status would be seen in public without wearing gloves. Considered to be symbolic of "luxury, elegance, refinement" as advocated by a 19th-century social handbook. Gloves were worn as an essential element to many styles of dress as well as playing a key symbolic role in reflecting the status of the wearer. For women, a slim and elegant hand was considered a sign of refined family background. Gloves, along with other accessories such as shoes, hats, and scarves, although secondary to the main fashion statement, have been significant in the careful construction of the overall sartorial effect in order to meet the requirements of the occasion or to portray a certain style of fashion. At the end of the 19th century and beginning of the 20th-century gloves were indicative of refinement and etiquette. Susan Vincent comments that "ongoing Victorian propriety coupled to the complexity of the Edwardian sartorial ethic, meant that outside the home gloves were almost always worn by the well-todo." (Vincent: 2012)

A close study of gloves offers the opportunity to draw conclusions about the wearer and the era or occasion on which they were worn and made. The fabric, the embellishments and certain details of design allow the observer to build a picture of the time. Gloves are very personal and, usually being made of leather, mould their shape to that of the wearer's hand. Handling a glove that belonged to a past era is akin to shaking the hand of the owner, providing a very personal connection. The survival of not only the gloves but the articles associated with them, different though they are, enables the possibility to analyse real lives. Therefore, gloves; "can reflect in fabric and stitches, the factual and emotional story of their life, qualities now well understood by collectors and curators." (Taylor, de la Haye, Thompson 2005: 14) An important advocate of material culture studies, Ann Smart Martin affirmed that: "Material objects matter because they are complex symbolic bundles of social, cultural and individual meanings fused into something we can touch, see and own" (Smart Martin 1993: 141)

The Glove Collection Trust oversees a collection of historic and modern gloves recognized as one of the finest in the world including a number of 17 th-century gloves. The historic gloves being on loan to the Fashion Museum in Bath. Dents possess a collection of historic gloves (some of which date to the company's origins in the 18th century) as well as currently caring for a collection of modern gloves owned by the Glove Collection Trust.

There are many challenges inherent in accessing glove collections, some not yet catalogued or photographed, some being privately owned, the condition of the gloves and textiles themselves can be problematic, provenance cannot be proven (particularly if anecdotally owned or worn by a famous person) and there can be lack of adequate information relating to the gloves themselves. 


\section{Worcester as a significant center of glove making and its background}

Worcester is a cathedral city and the county town of Worcestershire in England. The glove industry in Worcester began as far back as medieval times. D.C. Lye's comments in his seminal book 'The Leather Glove Industry of Worcester in the Nineteenth Century' that "references to glovers appear in Worcester Cathedral records as early as the thirteenth century" (1973: 8)

Records suggest that Worcester was an important centre of glove-making, notably from the late 15th century. With the glove-making industry in Worcester reaching its height in the late 18th and early 19th centuries (between 1790s and 1820s) when the city had more than 150 glove manufacturers and the superior quality of the make was recognized both nationally and internationally. It was a major centre for glove making, employing nearly half the glovers in England at its peak (over 30,000 people). Sixty percent of people in Worcester were engaged in glove manufacturing and the industry was booming. The normal glovemaking apprenticeship was 7 years, and upon completion led to the position of Master Cutter. It was a key part of a nationally acknowledged and important industry. Gloves were produced in Worcester until 2015 when the last great master craftsmen died, he was the last of the glove producers in the city (Worcester News: 2015). The geographical location of Worcester has been an important factor in its significance as a centre for gloves. The River Severn, overlooked by the 12 th-century cathedral, is found on the west side of the city centre, providing an important means of transportation to and from the port of Bristol, essential for finished gloves. There were tanneries throughout the country but Worcester had its own tanneries and, being close to the river, this created the opportunity of bringing the essential raw materials for the tanneries such as lime, imported bark, chromium salt (via Droitwich) and provided water for the tanneries and for the processing of animal skins for the leather. The necessary animal skins for tanning came via London or Bristol (where skins from Ireland were imported). Larger glove manufacturers had their own tanners within the business, otherwise the glove cutters received the prepared leather from the local tanners. The salt was used on the animal skins as part of the Chrome tanning process. This method resulted in softer and more pliable leather than a vegetable tanning process (producing a more rigid leather used primarily for luggage or the soles of shoes).

The industry was assisted by additional infrastructure in the area such as the Worcester and Birmingham Canal which opened in 1815 and the railway which reached Worcester in 1850. From 1880 horse-drawn trams ran in the streets. This made the movement of goods much easier and opened up the potential for goods to be transported to wider parts of the country.

The glove industry grew in the 19th Century as a replacement for the local wool broadcloth trade which had been in decline for some time due to competition from other local industries as well as the Worcester wool merchants stretching the fabric too much in the finishing and had completely faded away by end of the 18th century. The workforce from the declining broadcloth industry needed to find a new source of livelihood at the same time as more and more people were wearing gloves.

In the 1800s the sale of finished gloves was predominantly wholesale to London merchants. There was some export to Europe and the USA. In 1826 import duties on foreign gloves were removed resulting in a negative impact upon the glove industry in Worcester. Many companies in Worcester did not survive the challenging trading conditions resulting from these changes to import duties. Two companies who persisted were Dents and Fownes but only Dents as part of the Dewhurst Dent group today still manufacture gloves in England.

\section{Dents gloves background and stories of gloves viewed}

From 1777 onwards, fine quality gloves requiring skill and craftsmanship have been produced by Dents and by 1839 with an international reputation, they were exporting to the finest shops in Europe, North America, Asia, and Australia. Little has changed in their skilled glove-making process since those times, apart from the use of the sewing machine which was invented in the mid 19th century. Clearly the demand for gloves as an everyday accessory is 
somewhat reduced now compared to the turn of the 20th century due to a variety of social and sartorial reasons. As commented by Susan J. Vincent, 1900 "could be said to represent the zenith of glove-wearing" when any selfrespecting Victorian would not be seen without their hands being out of sight and encased in gloves. (Vincent: 2012). Changing fashions and social etiquette since the last century resulted in a significant decline in demand. As recently as the 1960s, there were approximately one hundred glove factories in England. However, since that time changing fashions and more affordable imports from overseas have resulted in the closure of numerous companies. Dents are one of just a handful of glove makers that have survived and who continue to thrive providing a high-quality product, to an appreciative international client base seeking a sophisticated accessory.

Dents were originally founded by John Dent, learner glove maker, in a tiny picket house in Worcester. In the following two centuries, business was very successful and the companybuilt manufacturing units throughout Europe, and opened workplaces and warehouses in New York, Montreal and Sydney.

In 1949 Dents as a manufacturer of gloves still retained factories in Worcester for production in addition to a manufacturing base near the city of Bath which included their main base today of Warminster. The organization relocated to Warminster (near Bath) in the 1930s.

Manufacturing also took place abroad and Dents gloves held in the Fashion Museum collection attest to this. Gloves can be found with stamped writing inside the wrist such as "Dents manufactured in France" or "Dents Worcester make". Interesting design details such as button fastenings on some gloves contain information such as "Dent Make" or the letter " $D$ " embossed or engraved.

Some interesting and significant pieces within the Dents museum collection are described here:

Black jersey gloves, belonging to Queen Victoria during her reign (1837-1901). Dents have retained their contact with the royal household, with the company selected to make both King George VI's coronation glove in 1937 and Queen Elizabeth II's in 1953 worn by Her Royal Highness at her coronation in Westminster Abbey on the 2nd of June 1953.
Prior to this, coronation gloves were made by Messrs. Harborows of London.

The 'Penny Purse' leather glove dating from around 1860, at a time when ladies never took their gloves off in public, the glove was designed and made with a tiny purse integral to the top of the glove on the back of the hand. The intention is to preserve the modesty of the wearer to allow payment of the fare to travel on the horsedrawn bus.

Limerick gloves were sold in a walnut shell case, these originated in the early part of the 19th century and were produced to the middle of the century, these were favoured by women who wanted to keep their hands white and soft. The concept and original design were thought to have originated in Co. Limerick in Ireland, but due to their popularity they were also later produced in other glove-making cities in England. The leather was so fine and thin that it could be folded up and placed inside a walnut shell. They were said to be produced from the skin of unborn calves, the leather was so very fine that sometimes the gloves could only be worn once. The hand-stitching carried out by women and girls was exactingly fine, being about thirty-two stitches to the inch. These were indicative of the social pressure of the times for women of a certain social level to maintain hands that were soft, smooth and refined in appearance.

\section{The Fashion Museum in Bath, Glove collection and exhibitions.}

The Fashion Museum, which is one of the world's great museums of historic and fashionable dress and accessories, has amongst its treasures a significant collection of gloves some of which belong to the Glove Collection Trust.

In 2017 the Fashion Museum presented a 'History of Fashion in 100 objects' in which gloves, housed at the Fashion Museum but on loan from the Glove Collection Trust were given prominence. The exhibition included gloves from the 17th century which are part of a unique example of 130 historical gloves that were owned by the late collector Robert Spence (1871-1964) who gifted the entire collection to the Worshipful Company of Glovers in 1959 with precise instructions that "The collection should remain intact in perpetuity..." (Fashion Museum) Apparently the first time that the 
collection was mentioned was in Connoisseur magazine in 1919.

Some of the gloves in the collection date from the time of William Shakespeare whose father, John, was identified as a glover in Stratford. In those times gloves were made in the home of the maker. Many of the gloves from those times are very ornate, highly embellished and decorative, all having been worked by hand. Some being of a gauntlet style or with long cuffs, incorporating motifs of flora and fauna (such as ladybirds, deer or bird) and embroidery designs even included motifs such as ladies in long dresses, all depicted through fine hand embroidery. Gauntlet gloves were popular from about 1610 to 1640. Hand lace trim and sometimes beadwork is in certain cases incorporated into the glove design. In some fine examples embroidered or stitched metallic threads glisten adding a sense of luxury and high status to the wearer particularly where the embellishment covers the entire gauntlet section of the glove. All embroidery or lace on gloves was handmade. Linen and silk were often used to produce bobbin lace by hand since it was not until 1828 that the first embroidery machines were introduced.

Examples of gloves from the 17th century are incredibly unusual to find in a museum collection today. There is notably a pair of gloves associated with King James I of England who reigned from 1603-1625, these are thought to have been a New year gift. According to Doris Langley Moore (founder of the Fashion Museum in 1964): “... contrary to what seems to be popular belief, museums do not abound in Elizabethan, Jacobean, Caroline costumes. These are, in fact, much scarcer than paintings by the greatest artists of the same periods. It is impossible for this or any museum to illustrate by means of actual specimens the progress of the mode in all its stages until we come well into the 18th century." (Fashion Museum, Bath).

Other examples of gloves made for royalty were shown in the exhibition at The Fashion Museum entitled 'Royal Women'. Princess Alexandra's mother in law was Queen Victoria through marriage in 1863 to Victoria's eldest son, the Prince of Wales, Albert Edward, known as Bertie. A copy of Princess Alexandra's coronation glove was on display. Some background to the coronation is helpful in appreciating the glove itself as well as the coronation dress and gown that it was designed to accompany. Queen Victoria died in 1901, Princess Alexandra became Queen Empress Consort to her newly crowned husband, King Edward VII. Alexandra was 58 years old and her husband was aged 61. After 38 years as Princess of Wales and queen in waiting, her husband has crowned Edward VII on 9th August 1902.

The coronation had been postponed from its originally scheduled date of 26th June due to Edward's diagnosis with appendicitis and immediate operation due to the grave nature of his illness. When the coronation finally took place, having waited all his life for this event, Edward scheduled a year and a half for the planning of the coronation to ensure a magnificent ceremony and spectacle that would do justice to the Empire.

The regal effect can be seen in the gloves made for the coronation by Messrs. Harborow of London. A duplicate glove was always produced in case of accidental damage or loss to the original. In 1972, Messrs. Harborow presented the duplicates to the Worshipful Company of Glovers of London who placed them in the care of the Fashion Museum in Bath. The glove was designed to complement the stunning coronation gown of heavy and plain gold silk gauze. Embroidered motifs proliferated, floral repeats interspersed with gold spangles across the bodice. Alexandra had developed her own unique style and had commissioned the intricately embellished net overdress incorporating metallic threads to be designed and produced in India. Therefore, no part of the coronation gown was made in the United Kingdom, although the gloves were made in England. The dramatic gown required dramatic gloves to complement and add to the sense of splendour and pageantry of the occasion. From 1901 onwards, Queen Alexandra as she was then, was the embodiment of turn of the century elegance. She presided over the gilded age of European Royalty that blossomed before the First World War. It is worth considering too, that 1903 was the beginning of the era of the Suffragettes.

Queen Victoria herself had ascended the throne in 1837. The coronation took place on 28th June 1838 at Westminster Abbey just over a year after she ascended to the throne of the United Kingdom at the age of 18. The replica coronation glove is held by the Fashion Museum in Bath. It was also made by Messrs. Harborow of $6 \mathrm{New}$ Bond Street in London. The glove is 
minute in size, reflecting the youthful age of Victoria and her diminutive height, famously tiny in stature she was $1.52 \mathrm{~m}$ tall. At the coronations of the British Monarchy, the sovereign's right-hand glove is removed and the coronation ring is put on. At the coronation the ring was unfortunately put onto the wrong finger by the Archbishop resulting in Victoria having with great difficulty to remove the ring which was both difficult and painful; she herself commented upon this in her own account of the proceedings. Commentators at the time noted that she appeared vulnerable and insecure at her coronation.

During the 64-year reign of Queen Victoria, 1837-1901 was the prime era for glovewearing. Any self- respecting Victorian had covered hands at all times when in society. In class-conscious 19th-century society, fashion was an important way of demonstrating both social position and wealth. Every activity required a different kind of gloves, and people were expected to possess not just a pair or two of gloves, but an entire glove wardrobe. Vincent's examples of the ubiquity of gloves may surprise our modern approach: "There were different shades, styles, fabrics, and fit for different times of day, times of year, and different activities." (Vincent: 2012).

Even though gloves were worn by women and men for activities such as sports or shooting guns, their cleanliness was paramount. Women could change their gloves multiple times throughout the day to ensure a spotless appearance. For the rich glove wearer, these accessories were not regarded as repairable. Rather, they were seen as completely expendable, an item of clothing that, though necessary, could be and was replaced constantly. Poor people, however, would clean their gloves and repair them until they inevitably fell apart. Special soap existed for cleaning leather gloves in more recent times and Dents produced their own branded version, of which there is an example in their archive.

\section{The Milore Glove collection}

A much later addition to the Worcester Glove manufacturing industry, Milore glove factory operated from 1946 to 1981. It was the secondlast glove company in Worcester, employing mostly women and young girls who had to undergo 6 weeks of intensive training to qualify as a skilled glove maker. They were paid for each pair produced so they had to be quick and produce good quality gloves. Many women left the factory once they got married but many were able to continue to earn money by having a sewing machine at home. Being an outworker was a means of remaining employed after marriage. There was clearly a community spirit amongst the workforce, which was depicted in the 2005 play entitled 'Gloves Galore', written and directed by local women who had been employed at the factory for 34 years. It captures the strong community spirit amongst the employees who enjoyed staff trips to the seaside and who socialized outside of work by going dancing together. It was initially staged at a local theatre and was enthusiastically reviewed in the Worcester News: "It was charming production based on the day-to-day workings of the former Bromyard glove factory, Milore. Its forte was in capturing a sense of nostalgia with big efforts being made to create a 1950s set, with foot-controlled sewing machines, clockingin machine, telephones, furniture, and wonderful costumes and hair-do's." (Hardy: 2005)

The company specialized in producing high fashion women's gloves and commissioned up and coming designers to develop the appeal of fashionable brands. The gloves and other artefacts such as photographs, leather colour cards, letters and glove patterns, were saved for future reference when the factory finally closed. The Museums Worcestershire archive collection contains numerous pairs of unworn Milore, brand-new leather gloves in an array of bright jewel colours, still in their cellophane wrappers. Gloves in a range of exciting colours including powder blue, fuchsia, buttercup yellow, and turquoise can be seen with a range of different pattern effects. Bows, embroidery, cut-out pattern effects, ruching, and many other intricate and unusual design details can be seen.

There are examples of gloves produced for the fashion house of Christian Dior. In 1949 the autumn collection by Dior became known as the mid-century look. Gloves were a very important part of this triumphant collection. "Sleeves were often three-quarter length, which meant, in the dramatic words of French Vogue, that "the reign of the glove had begun": gloves and umbrellas were now 'indispensable accessories'”. (Keenan: 56). The following autumn of 1950, gloves were still an important 
accessory for Dior. "Vogue especially liked the new Dior accessories: a gauntlet glove with a cuff so deep it could contain a purse" (Keenan, B: 69). It is unusual to find a photograph of a Dior design, either day or evening wear when the model is not wearing gloves. The feminine evening clothes often with plunging necklines of soft chiffons or stiff silks were worn with gloves. It is not clear if the Milore gloves for Dior were only sold in England or were also exported abroad.

Milore set out to work with designers both well-known and also with up and coming designers. There is archival evidence of a handdrawn design by Manolo Blahnik, early in his career in London in 1969, when he purchased the Chelsea boutique, Zapata, to run as his own business venture. It was at the beginning of his career when he was writing for both L'Uomo Vogue and The Sunday Times that in addition to designing gloves, he started designing men's shoes.

Examples of hand-drawn glove designs for Milore, produced by design students are also part of the Worcestershire collection and the company was very significant in the latter stage of the glove industry in Worcester because of its innovative approach to design. The last Managing Director of Milore gave his significant collection of gloves to Worcester City in 2001, and several years later, his family donated his research writings and other artefacts and items associated with the glove industry. (Research Worcestershire: 2014)

\section{Conclusion}

In conclusion, researching beautifully designed and exquisitely made gloves is a visual and material pleasure. Some examples viewed have been worn (one can only imagine by whom), some are still in their original wrapper, straight from those who made and packed them. The variety of design and extent of embellishment has over the centuries significantly changed to adapt to the social etiquette and fashions of the day. At all times gloves have been and still are considered are a key part of an outfit; be it for symbolism, social etiquette, to portray wealth and status, as a key fashion statement, for protection, or as part of a uniform.

The gloves themselves cannot, however, be studied without a connection to the realities of glove making, that was originally carried out in family homes, to artisan craftsmanship or to the mass production of more recent times. The glove has at times provided a significant livelihood to those involved with its design and making. Its use has been both sartorial and functional, and glove collections and artefacts from past times provide a valuable resource for insights into social history of the labour required for their production as well as the social etiquette surrounding their wear.

The fascinating examples of gloves that exist in the key collections addressed in this paper provide the long- term opportunity for the inspiration and education of designers and manufacturers to look at design details of exquisite craftsmanship and provide the opportunity to be inspired by the past. Their existence must be preserved for future generations as they give important insight into a time of different values and design skills. Ultimately, they provide the opportunity for the contextualization of a period of history through its surviving material culture. 


\section{References}

de Marly, D. (1990). Fashion Designers. Christian Dior. London: BT Batsford Ltd.

Hardy, A. (2005) Gloves Galore $n$ Review: Conquest Theatre (online) Worcester News. Available at: http://www.worcesternews.co.uk/news/7448691.Gloves_Galore_n_Review_Conquest_Theatre/ (accessed 18 Jun 2018)

Keenan, B. (1981). Dior in Vogue. pp.56, 69

Lyes, D.C. (1973). The Leather Glove Industry of Worcester in the Nineteenth Century. Worcester: Worcester City Museum and Art Gallery.

Research Worcestershire. (2014). Glove collections. (online) Available at: https://researchworcestershire.wordpress.com/2014/08/05/glove-colletions/ (accessed 17 Jun.2018).

Redwood, J. (2016). Gloves and Glove-Making. China: World Print Ltd. pp.28-29

Smart Martin, A. (1993), 'Makers, Buyers, and Users, Consumerism as a Material Culture Framework', Winterthur Portfolio, vol.8, no.2/4, Summer/Autumn, pp. 141-157

Steele, V. (1998) 'A Museum of Fashion is More Than a Clothes Bag', Fashion Theory, vol.2, no.4, pp 327-335

Strasdin, K. (2017) Inside the Royal Wardrobe. A Dress History of Queen Alexandra. London: Bloomsbury.

Taylor, L. de la Haye, A. and Thompson, E. (2005), A family of fashion, The Messels: Six Generations of Dress, London Philip Wilson Publishers.

Vincent, S. (2012) 'Gloves in the Early Twentieth Century: An Accessory After the Fact', Journal of design history, vol. 25, No.2. Oxford: Oxford University Press. 